\title{
Hyperpigmentation and ACTH - an overview of literature
}

\author{
Florica Sandru, ${ }^{1,2}$, Mihai Cristian Dumitrascu²,3 Simona Elena Albu²,3, \\ Mara Carsote ${ }^{2,4}$, Ana Valea ${ }^{5,6}$ \\ ${ }^{1}$ Elias Emergency University Hospital, Bucharest, Romania \\ 2"Carol Davila" University of Medicine and Pharmacy, Bucharest, Romania \\ 3 Emergency University Hospital, Bucharest, Romania \\ 4"C.I. Parhon" National Institute of Endocrinology, Bucharest, Romania \\ ${ }^{5}$ Clinical County Hospital, Cluj-Napoca, Romania \\ 6"Iuliu Hatieganu" University of Medicine and Pharmacy, Cluj-Napoca, Romania
}

\begin{abstract}
Introduction. ACTH (adrenocorticotropic hormone) is a key regulator of adrenal production involving cortisol as an essential hormone for life. The melanin is a pigment which is produced by melanocytes at the level of melanosomes (the melanogenesis). Both MSH and ACTH are generated by the cleavage of POMC (proopiomelanocortin) after CRF (corticotropin-releasing factor) stimulation and then MSH acts on the skin causing hyperpigmentation.

Aim. To introduce clinical data of literature that link hyperpigmentation with ACTH excess. Three main topics are introduced: Addison's disease, ectopic Cushing's syndrome, and Nelson's syndrome.

Method. This is a short overview of literature including papers that have been mostly published within last 5 years.

General data. Hyperpigmentation in relationship to ACTH includes its high levels in addition to low cortisol in Addison's disease and Nelson's syndrome and high non-suppressible cortisol in ectopic Cushing's disease. $\mathrm{ACTH}$ has a pituitary origin in first two situations and malignancy in the third one. A pituitary tumour is found in cases with Nelson's syndrome. An autoimmune background may be associated with Addison's disease. An iatrogenic component is brought by Nelson's syndrome. All three situations are severe and life threatening of different scenarios.

Conclusion. Hyperpigmentation may be the clue to connect dermatology to endocrine pathologies and ACTH massive release by a pituitary or a non-pituitary origin involves a complex panel of conditions.
\end{abstract}

Keywords: hyperpigmentation, ACTH, Nelson's syndrome, Addison's disease, ectopic Cushing's syndrome

\begin{abstract}
Abbreviations
ACTH = adrenocorticotropic hormone

ASP $=$ Agouti signalling protein

$\mathrm{MSH}=$ melanocyte stimulating hormone

$\mathrm{CRF}=$ corticotropin-releasing factor

$\mathrm{MC1R}=$ melanocortin receptor type 1

$\mathrm{PET}=$ positron emission therapy
\end{abstract}

\section{INTRODUCTION}

ACTH (adrenocorticotropic hormone) is a key regulator of adrenal production involving cortisol as an essential hormone for life $(1,2)$. The steroid secretion is normally the effect of a complex frame that also includes autocrine and paracrine factors $(1,2)$. Even chromaffin cells from medullary part of the adrenal glands may produce ACTH as the pituitary gland does $(1,2)$. ACTH acts not only as a hormone at the level of adrenal glands but also at the level of blood vessels and a local mediator at adrenals $(1,2)$. ACTH also has a role as an acute regulator of aldosterone production as well as serotonin $(2,3)$. 
Beyond endocrine and cardiovascular connections, ACTH is also linked to the skin and melanogenesis and this goes through MSH (melanocyte stimulating hormone) interplay $(4,5)$. Alpha-MSH is a regulator of pigmentation in normal humans $(5,6)$. This is done in association with other melanocortins whose roles are more or less understood until present time $(5,6)$. Alpha-MSH as well as ASP (Agouti signalling protein) acts on melanocortin receptor type 1 (MC1R) of melanocytes displaying melanogenic effects, but also mitogenic actions $(5,6)$. Skin melanocytes are activated by paracrin and autocrin factors, for instance, in case of prolonged sun exposure $(5,6)$. The melanin is a pigment which is produced by melanocytes at the level of melanosomes (the melanogenesis) (6). Both $\mathrm{MSH}$ and ACTH are generated by the cleavage of POMC (proopiomelanocortin) after CRF (corticotropin-releasing factor) stimulation $(6,7)$. The acquired hyperpigmentation it comes with an abnormal ACTH in parallel with high MSH as it happens in ACTH tumour-derivate secretion of pituitary and non-pituitary origin $(5,6,7)$.

\section{AIM}

To introduce clinical data of literature that link hyperpigmentation with ACTH effects at the level of the skin. Three main topics are introduced: Addison's disease, ectopic Cushing's syndrome, and Nelson's syndrome. All these conditions are associated with high levels of ACTH of either pituitary or non-pituitary tumour as cause, benign or malign, and this goes with hyperpigmentation.

\section{MATERIAL AND METHOD}

This is a short overview of literature including papers that have been mostly published within last 5 years regarding medical data that involves high $\mathrm{ACTH}$ and skin hyperpigmentation. A selection of 30 papers is done.

\section{GENERAL DATA}

\section{Addison's disease}

Addison's disease is a rare, heterogeneous condition where the destruction of the adrenal glands is done mainly based on an autoimmune or tubecurculosis background (8). Low cortisol causes an ACTH increase based on a feedback mechanism between pituitary and adrenal glands while hyperpigmentation at the level of skin (including scars) and mucosa is one of the main clinical features (9). Others skin conditions like vitiligo may be associated in cases with polyglandular autoimmune syndrome (10). Primary adrenal insufficiency may be lethal if adequate substitution is not provided (9). More than 30 causes are described, including genetic types (9).

\section{Ectopic Cushing's syndrome}

Cushing's syndrome is the excess of glucocorticoid of either endogenous or exogenous cause $(11,12)$. Endogenous sources includes the adrenal itself and ACTH derivate forms like corticotropinoma and ectopic Cushing's syndrome (also called ACTH-dependent types) $(11,12)$. This last mentioned type comprises between $10 \%$ and $20 \%$ of all ACTH-dependent cases $(11,12)$. The cause of ACTH is a non-pituitary tumour despite the fact that a concomitant pituitary incidentaloma might be registered due to the high prevalence in general population $(13,14,15,16)$. The most frequent forms of cancer causing ectopic Cushing's syndrome are located in thorax-abdominal region $(12,17)$. Among them we mention small cell lung carcinoma, medullary thyroid cancer, neuroendocrine tumours of the lung and gastro-intestinal tract $(17,18,19,20)$. The typical endocrine assessment includes the confirmation of persistent cortisol secretion which is not suppressible at high-dose dexamethasone suppression test $(18,19)$. The imaging tests are complex from computed tomography, magnetic resonance imaging up to PET (positron emission therapy) imaging $(18,19)$. The therapy targets the specific profile of the causing tumour and, in cases with unknown/unidentified cause, bilateral adrenalectomy might be necessary to control the damage due to Cushing's syndrome (21). In these cases the CRF but mostly the ACTH excess associates with hyperpigmentation even in a relative short period of time (19).

\section{Nelson's syndrome}

Nelson's syndrome represents another particular situation where ACTH increase is part of the pathogenic loop and its values can get extremely high $(22,23,24)$. This happens after bilateral adrenalectomy for Cushing's disease and it represents a rather atypical option nowadays due to others several medical and surgical therapeutical resources which are preferred $(22,25,26)$. The complication is rare; it involves high ACTH with known complications including the skin, and corticotropinoma enlargement $(26,27)$. Prior radiotherapy might be protec- 


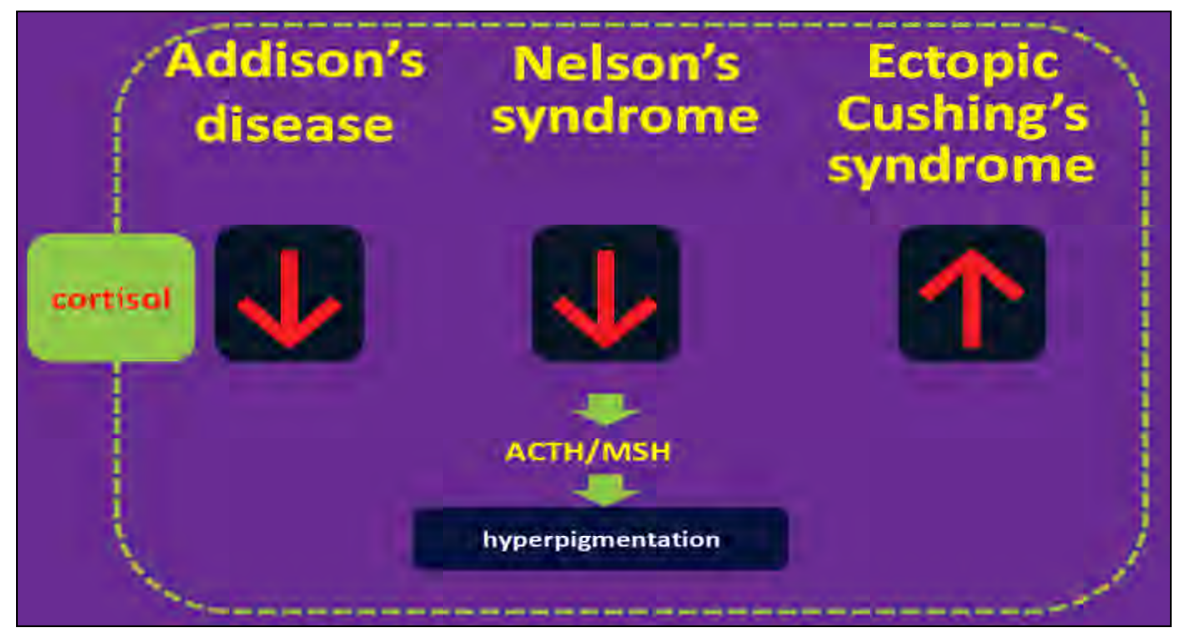

FIGURE 1. Conditions with high ACTH and hyperpigmentation

tive, yet the general data are inconclusive $(26,27)$. There is not general guideline as approach but radiotherapy, neurosurgery of the pituitary gland an and potential use of somatostatin analogues and/or dopamine agonists are the therapy lines $(26,27)$. A study published in 2019 showed that $38 \%$ of the subjects with Nelson's syndrome displayed some level of progression during a follow-up of 10 years (28). The risk of progression is higher if complex therapies are applied to Cushing's disease but this may also be correlated with a more severe form of disease (28). Nelson-Salassa syndrome has been revealed in half of the persons with Cushing's disease treated with bilateral adrenal removal associating a mild evolution (29). A few cases are described actually underling a pituitary ACTHproducing carcinoma (29). This is suspected in rapidly growing tumours and ACTH increase with suggestive symptoms (29). Despite this potential severe complication, difficult cases of Cushing's disease should still be treated with synchronous bilateral adrenalectomy (30).

\section{REFERENCES}

1. Lefebvre $\mathrm{H}$, Thomas M, Duparc C, Bertherat J, Louiset E. Role of ACTH in the Interactive/Paracrine Regulation of Adrenal Steroid Secretion in Physiological and Pathophysiological Conditions. Front Endocrinol (Lausanne). 2016 Jul 20;7:98.

2. El Ghorayeb N, Bourdeau I, Lacroix A. Role of ACTH and Other Hormones in the Regulation of Aldosterone Production in Primary Aldosteronism. Front Endocrinol (Lausanne). 2016 Jun 27;7:72.

3. Carsote M, Radoi V, Geleriu A, Mihai A, Ferechide S, Opris D, Paun $\mathrm{D}$, Poiana $\mathrm{C}$. The serotonin and the bone assessment. Journal of Medicine and Life 2013; 6(2):151-155.

4. Portaluppi $F$. The circadian organization of the cardiovascular system in health and disease. Indian J Exp Biol. 2014 May; 52(5):395-8.

5. Abdel-Malek Z, Suzuki I, Tada A, Im S, Akcali C. The melanocortin-1 receptor and human pigmentation. Ann N Y Acad Sci. 1999 Oct 20; 885:117-33.

\section{DISCUSSION}

Overall, hyperpigmentation in relationship to ACTH includes its high levels in addition to low cortisol in Addison's disease and Nelson's syndrome and high non-suppressible cortisol in ectopic Cushing's disease. ACTH has a pituitary origin in first two situations and malignancy in the third one. A pituitary tumour is found in cases with Nelson's syndrome. An autoimmune background may be associated with Addison's disease. An iatrogenic component is brought by Nelson's syndrome. All three situations are severe and life threatening of different scenarios (Figure 1).

\section{CONCLUSION}

Hyperpigmentation may be the clue to connect dermatology to endocrine pathologies and $\mathrm{ACTH}$ massive release by a pituitary or a non-pituitary origin involves a complex panel of conditions.

6. Videira IF, Moura DF, Magina S. Mechanisms regulating melanogenesis. An Bras Dermatol. 2013 Jan-Feb; 88(1):76-83.

7. Slominski AT, Zmijewski MA, Zbytek B, Tobin DJ, Theoharides TC, Rivier J. Key role of CRF in the skin stress response system. Endocr Rev. 2013 Dec; 34(6):827-84.

8. Hinz LE, Kline GA, Dias VC. Addison's Disease in Evolution: An Illustrative Case and Literature Review. Endocr Pract. 2014 Sep; 20(9):e176-9.

9. Buonocore F, Achermann JC. Primary adrenal insufficiency: New genetic causes and their long-term consequences. Clin Endocrinol (Oxf). 2019 Oct 14.

10. Frommer L, Kahaly GJ. Autoimmune Polyendocrinopathy. J Clin Endocrinol Metab. 2019 Oct 1; 104(10):4769-4782.

11. Lacroix A, Feelders RA, Stratakis CA, Nieman LK. Cushing's syndrome. Lancet. 2015 Aug 29; 386(9996):913-27. 
12. Decaestecker K, Wijtvliet V, Coremans P, Van Doninck N. Olfactory neuroblastoma (esthesioneuroblastoma) presenting as ectopic ACTH syndrome: always follow your nose. Endocrinol Diabetes Metab Case Rep. 2019 Oct 17; 2019.

13. Gheorghiu M, Hortopan D, Dumitrascu A, Caragheorgheopol A, Stefanescu A, Trifanescu R, Niculescu D, Baciu I, Carsote M, Poiana C, Badiu C, Coculescu M. Age-related endocrine tumors: nonfunctioning adrenal tumors as compared to pituitary adenomas. Acta Endocrinologica, 2009; V(3):371-384.

14. Gheorghisan-Galateanu AA, Carsote $M$, Valea A. Incidentaloma: from general practice to specific endocrine frame. J Pak Med Assoc. 2017.67(6):917-922.

15. Poiana C, Chirita C, Carsote M, Hortopan D, Goldstein A. Galactocele and prolactinoma - A pathogenic association?, Maturitas. 2009; 62(1):98-102.

16. Carsote M, Chirita C, Dumitrascu A, Fica S, Poiana C. Pituitary incidentalomas-How often is too often? Journal of Medicine and Life, 2009; 2(1):92-97.

17. Raff $\mathrm{H}$. Cushing syndrome: Update on testing. Endocrinol Metab Clin North Am. 2015 Mar; 44(1):43-50.

18. Witek P, Witek J, Zieliński G, Podgajny Z, Kamiński G. Ectopic Cushing's syndrome in light of modern diagnostic techniques and treatment options. Neuro Endocrinol Lett. 2015; 36(3):201-8.

19. Santhanam P, Taieb D, Giovanella L, Treglia G. PET imaging in ectopic Cushing syndrome: A systematic review. Endocrine. 2015 Nov; 50(2):297-305.

20. Valea A, Radu O, Morar A, Ghemigian A, Carsote M. Synchronous medullar thyroid cancer and primary hyperparathyroidism on a female within the sixth decade of life with positive family history for type $2 \mathrm{~A}$ MEN syndrome. Journal of Medical Practice. 2016; 4(47)-11:346-349.

21. Paduraru DN, Nica A, Carsote M, Valea A. Adrenalectomy for Cushing's syndrome: do's and don'ts. Journal of Medicine and Life. 2016; 4(9):334-341.
22. Nica AE, Carsote M, Paduraru DN, Valea A. Bilateral adrenalectomy and Nelson's syndrome. Archives of Balkan Medical Union. 2016; 51(2):280-283.

23. Valea A, Ghervan C, Carsote M, Albu SE, Georgescu CE. Different surgical options in Cushing's disease. Journal of Surgical Sciences. 2016; 3(1):39-43.

24. Poiana C, Chirita C, Carsote M, Hortopan D, loachim D, Corneci CM, Stanescu B. Adrenal and Pituitary Incidentalomas in a Case of Cushing's Syndrome. Chirurgia 2013; 6(108):886-891.

25. Carsote M, Ghemigian A, Valea A, Dumitrascu A, Chirita C, Poiana C. Sublinical Cushing's syndrome with bilateral adrenal tumours in a patient with gallbladder multiple stone: Therapeutical options. Ars Medica Tomitana. 2015; 3(21);124-127.

26. Iglesias $P$, Rodríguez-Berrocal V, Pian H, Díez JJ. Nelson's syndrome post-bilateral adrenalectomy. QJM. 2016 Aug; 109(8):561-2.

27. Palermo NE, Ananthakrishnan S. Re-examining Nelson's syndrome. Curr Opin Endocrinol Diabetes Obes. 2015 Aug; 22(4):313-8.

28. Fountas A, Lim ES, Drake WM, Powlson AS, Gurnell M, Martin NM, Seejore K, Murray RD, MacFarlane J, Ahluwalia R, Swords F, Ashraf M, Pal A, Chong Z, Freel M, Balafshan T, Purewal TS, Speak RG, Newell-Price J, Higham CE, Hussein Z, Baldeweg SE, Dales J, Reddy N, Levy MJ, Karavitaki N. Outcomes of patients with Nelson's syndrome after primary treatment: A multicenter study from 13 UK Pituitary centers. J Clin Endocrinol Metab. 2019 Nov 18.

29. Carlstrom LP, Graffeo CS, Perry A, Stokken JK, Van Gompel JJ. Nelson-Salassa Syndrome Progressing to Pituitary Carcinoma: A Case Report and Review of the Literature. Cureus. 2019 Sep 8; 11(9):e5595.

30. Chiloiro S, Giampietro A, Raffaelli M, D’Amato G, Bima C, Lauretti L, Anile C, Lombardi CP, Rindi G, Bellantone R, De Marinis L, Pontecorvi A, Bianchi Synchronous bilateral adrenalectomy in ACTH-dependent hypercortisolism: predictors, biomarkers and outcomes. Endocrine. 2019 Dec; 66(3):642-649. 